\title{
Failure to Recover from Proactive Semantic Interference Differentiates Amnestic Mild Cognitive Impairment and PreMCI from Normal Aging after Adjusting for Initial Learning Ability
}

\author{
Rosie E. Curiel ${ }^{1 *}$, Elizabeth A. Crocco ${ }^{1}$, Arlene Raffo ${ }^{1}$, Salvador M. Guinjoan ${ }^{2}$, Charles Nemeroff ${ }^{1}$, \\ Ailyn Penate ${ }^{1,3}$, Daema Piña1, David A. Loewenstein ${ }^{1,3}$ \\ ${ }^{1}$ Department of Psychiatry and Behavioral Sciences, Center on Aging, Miller School of Medicine, \\ University of Miami, Miami, USA \\ ${ }^{2}$ FLENI Foundation, University of Buenos Aires Schools of Medicine and Psychology, Buenos Aires, Argentina \\ ${ }^{3}$ Wien Center for Alzheimer's Disease and Memory Disorders, Mount Sinai Medical Center, Miami Beach, USA \\ Email: *RCuriel2@miami.edu
}

How to cite this paper: Curiel, R.E., Crocco, E.A., Raffo, A., Guinjoan, S.M., Nemeroff, C., Penate, A., Piña, D. and Loewenstein, D.A. (2018) Failure to Recover from Proactive Semantic Interference Differentiates Amnestic Mild Cognitive Impairment and PreMCI from Normal Aging after Adjusting for Initial Learning Ability. Advances in Alzheimer's Disease, 7, 50-61.

https://doi.org/10.4236/aad.2018.72004

Received: October 23, 2017

Accepted: June 22, 2018

Published: June 25, 2018

Copyright (c) 2018 by authors and Scientific Research Publishing Inc. This work is licensed under the Creative Commons Attribution International License (CC BY 4.0).

http://creativecommons.org/licenses/by/4.0/

\begin{abstract}
Background: There is increasing evidence that the failure to recover from proactive semantic interference (frPSI) may be an early cognitive marker of preclinical Alzheimer's disease (AD). However, it is unclear whether frPSI effects reflect deficiencies in an individual's initial learning capacity versus the actual inability to learn new semantically related targets. Objective: The current study was designed to adjust for learning capacity and then to examine the extent to which frPSI, proactive semantic interference (PSI) and retroactive semantic interference (RSI) effects could differentiate between older adults who were cognitively normal $(\mathrm{CN})$, and those diagnosed with either Pre-Mild Cognitive Impairment (PreMCI) or amnestic MCI (aMCI). Methods: We employed the LASSI-L cognitive stress test to examine frPSI, PSI and RSI effects while simultaneously controlling for the participant's initial learning capacity among $50 \mathrm{CN}, 35 \mathrm{aMCI}$, and 16 PreMCI participants who received an extensive diagnostic work-up. Results: aMCI and PreMCI participants showed greater frPSI deficits (50\% and $43.8 \%$ respectively) compared to only $14 \%$ of CNparticipants. PSI effects were observed for aMCI but not PreMCI participants relative to their CN counterparts. RSI failed to differentiate between any of the study groups. Conclusion: By using participants as their own controls and adjusting for overall learning and memory, it is clear that frPSI deficits occur with much greater frequency in individuals at higher risk for Alzheimer's disease (AD), and likely reflect a failure of brain compen-
\end{abstract}


satory mechanisms.

\section{Keywords}

MCI, Alzheimer's Disease, Semantic Interference, Memory

\section{Introduction}

There is a growing concern about the efficacy of traditional paradigms used to diagnose the subtle cognitive changes that emerge during the pre-symptomatic stages of Alzheimer's disease (AD). Once an individual develops cognitive deficits, notably impairment in their memory or thinking abilities, significant brain compromise has already occurred, which hinders treatment effectiveness. To that end, efforts have been made to develop preventive and early targeted interventions for individuals at risk of developing AD. Similarly, the field now confronts the need to develop novel cognitive assessment paradigms that exploit vulnerabilities in persons with incipient $\mathrm{AD}$ to aid in early diagnosis and serve as clinically meaningful endpoints from which to establish treatment efficacy. Ideally, these tests would employ methodologies that are even more cognitively challenging, and are sufficiently sensitive and specific to capture early cognitive changes associated with $\mathrm{AD}$.

A major limitation of most existing memory measurement paradigms such as list-learning tests is that learning is relatively passive and they do not employ controlled learning paradigms during initial acquisition, such as category cues. Such controlled learning minimizes individual differences in initial learning strategies and the effects of cognitive reserve [1] [2]. While there have been attempts to assess proactive and retroactive interference, $\mathrm{AD}$ is denoted by specific deficits in semantic memory, and the inability to adequately access semantic lexicon [3]. While some traditional list-learning measures attempt to investigate proactive interference effects, most do not emphasize proactive semantic interference (PSI), and more importantly, none investigate recovery from PSI effects.

Recently, we developed a novel semantic interference paradigm the Loewenstein-Acevedo Scales for Semantic Interference and Learning (LASSI-L) [4] [5], which employs controlled learning and semantic cues at both acquisition and retrieval to reduce variability in individual learning strategies, and to maximize the storage and consolidation of 15 to-be-remembered targets in a wordlist (List A). These same cues are employed for learning 15 additional words (List B) belonging to the identical semantic categories as the initial target list (List A). Inefficient learning of the new wordlist may be due to PSI effects belonging to the shared semantic categories. A second cued recall trial of List B targets affords the opportunity to recover from the effects of PSI. The inability to recover from PSI effects after two learning trials is referred to as the failure to recover from PSI (frPSI). FrPSI effects are able to differentiate between aMCI and cognitively 
normal groups [4] [6], which are associated with MRI volumetric reductions in $\mathrm{AD}$ prone regions in aMCI adults [7], and regional amyloid load in cognitively normal elders reside in the community [8].

One potential criticism of these previous investigations is that failure to recover from proactive semantic interference, as measured by performance on the second cued recall trial (List B) on the LASSI-L, might be affected by other variables such as poor initial learning capacity or general retrieval deficits. In the present investigation, we employed different statistical approaches to the assessment of PSI, frPSI, and RSI by adjusting for an individual's own initial learning ability, and determined the ability of these corrected PSI, frPSI and RSI values to discriminate between $\mathrm{CN}$, aMCI and PreMCI groups. It was hypothesized that even after adjusting for the strength of initial memory performance, PreMCI and aMCI participants would evidence more difficulties with frPSI as compared to normal controls. No increased difficulties with RSI were hypothesized to occur across groups.

\section{Methods}

We recruited 101 English-speaking participants (38 males and 63 females) to the DETECT-pAD longitudinal aging study at the University of Miami Leonard M. Miller School of Medicine from March 2015 through October 2017. The study was reviewed and approved by the University of Miami Miller, School of Medicine, Institutional Review Board and all participants were formerly consented to participate in the study. All participants were administered a common clinical assessment protocol, the Clinical Dementia Rating Scale (CDR) [9], and the Mini Mental State Examination (MMSE) [10]. Memory and other cognitive complaints were assessed by clinical neuropsychology faculty members (RC and DL) and postdoctoral neuropsychology fellows who were blind to the neuropsychological test results and had formal training in administering the CDR. The 101 participants were all community-dwelling older adults who were independent in their activities of daily living, had knowledgeable collateral informants, and did not meet DSM-5 criteria for Major Neurocognitive Disorder, current major depressive episode or any other neuropsychiatric disorder. In cases where there was evidence of cognitive decline by history and/or clinical examination, the clinician scored the Global CDR as 0.5 were considered a diagnosis of MCI based on their examination, pending the results of formal neuropsychological testing. Subsequently, a standard neuropsychological battery was administered and conducted independent of the clinical examination. This protocol included the Hopkins Verbal Learning Test-Revised (HVLT-R) [11], delayed recall from the Logical Memory subtest of the National Alzheimer's Coordinating Center Uniform Dataset Neuropsychological Battery [12], Controlled Oral Word Association Test (FAS) [13], Category Fluency (Animals, Fruits, and Vegetables) [13], the Block Design subtest of the Wechsler Adult Intelligence Scales-Fourth Edition [14], and Parts A and B of the Trail Making Test [15]. 


\subsection{Diagnostic Groups}

\subsubsection{Criteria for Cognitively Normal $(\mathrm{CN})$ Participants $(n=50)$}

Following an extensive clinical interview, participants in this diagnostic group evidenced the following: 1) no subjective complaints related to memory or cognitive impairment during a clinical interview with the participant and collateral informant; 2) no clinical evidence or history of cognitive decline; 3) a Global CDR score of 0 that was determined by a trained clinician; and 4) all memory and non-memory neuropsychological measures scored within normal limits relative to age and education related norms (i.e., less than 1.0 SD below normative values for all tests).

\subsubsection{Criteria for PreMCI Participants ( $\mathrm{n}=16)$}

Participants in this diagnostic group evidenced the following: 1) subjective memory complaints by the participant and/or or collateral informant; 2) evidence by clinical evaluation or history of memory decline; 3) a Global CDR score of 5 ; 4) all memory and non-memory neuropsychological measures determined to be within normal limits relative to age and education related norms (i.e., less than 1.0 SD below normative values for all tests).

\subsubsection{Criteria for Amnestic MCI (aMCI) Participants ( $\mathrm{n}=35)$}

Individuals were classified as aMCI if they evidenced the following: 1) subjective memory complaints reported by the participant and/or collateral informant; 2) evidence by clinical evaluation or history of memory decline; 3) Global CDR score of $0.5 ; 4$ ) one or more memory measures $1.5 \mathrm{SD}$ or below normal limits relative to age and education related norms.

\subsection{Loewenstein-Acevedo Scales for Semantic Interference and Learning (LASSI-L)}

This novel cognitive stress test uses controlled learning and cued recall to maximize storage of an initial list of to-be-remembered targets that represent three semantic categories. What is unique about the measure is the presentation of another list of to-be-remembered targets that shares the same semantic categories, which are fruits, musical instruments and articles of clothing. Shared semantic categories elicit a considerable amount of proactive semantic interference. Unlike other memory paradigms, the individual is again administered this second list of targets to measure recovery from proactive semantic interference effects. Retroactive semantic interference and delayed recall are also assessed. The specific elements of the test are described below.

The participant is first instructed to remember a list of 15 common words that are fruits, musical instruments and articles of clothing (five words per category). The person is then asked to read the words from the target list aloud, as each word is presented individually at 4 -second intervals. In the unlikely event that the person cannot correctly read the word, the word is read by the examiner and the person is asked to repeat the word. If a person does not know one of the words (also unlikely), the examiner tells the person what category the word be- 
longs to (e.g., "Lime is a fruit"), and the person is asked to repeat the word. After the person has read all 15 words, they are asked to recall the words in any order. Following the free recall trial, the participant is presented with each category cue (e.g., clothing) and is asked to recall the words that belonged to that category (LASSI-L A1). The participant is then presented with the target stimuli for a second learning trial with subsequent cued recall to strengthen the acquisition and recall of the List $A$ targets, providing maximum storage of the to-be-remembered information (LASSI-L A2). Following this trial, the participant is exposed to a semantically related list (i.e., List B) that is presented in the same manner as List A. List B consists of 15 words that are different from List A, but belong to each of the three categories also used in List A (i.e., fruits, musical instruments, and articles of clothing). Following the presentation of the List $\mathrm{B}$ words, the person is asked to freely recall the List B words; this assesses proactive interference effects (LASSI-L B1). Then, each category cue is given, and the participant is asked to recall each of the List B words that belonged to each of the three categories. Importantly, List B words are presented once again, followed by a second category-cued recall trial. Finally, to assess retroactive interference, the participant is cued to recall the original List A words (LASSI-L A3). This second cued recall trial for the new list allows the assessment of the ability to recover from the initial semantic interference effects (LASSI-L B2). This recovery from proactive interference is a feature of the LASSI-L that is not assessed by any existing list-learning measure [3]. Test-retest reliabilities of the LASSI-L have been shown to be high in previous studies, and the accuracy of classification of aMCI patients versus cognitively normal elderly exceeded 90\% [4] [5].

\subsection{Statistical Analyses}

Analyses of means for demographic information were conducted using a series of one-way analyses of variance (ANOVAs). Following a statistically significant test of $p<0.05$, post-hoc tests of means were examined using the Tukey's Honestly Significant Difference (HSD) test. To control for initial learning effects, a PSI ratio score was developed for both free and cued recall of List $\mathrm{B}$, using the formulas List B1 Free Recall/List A1 Free Recall and List B1 Cued Recall/List A1 Cued Recall. A frPSI ratio was calculated using the formula List B2 Cued Recall/List A2 Cued Recall, and an RSI ratio was conducted using the formula List A3 Cued Recall/List A2 Cued Recall. In addition to PSI, frPSI and RSI ratios, the performance of $\mathrm{CN}$ individuals were compared to individuals diagnosed with aMCI and PreMCI using a series of 2 Group (e.g., CN versus aMCI) X Measurement (e.g., total raw score on List A Cued1 Recall versus total raw score on List B2 cued recall). Mixed model repeated measures ANOVA. Main and interaction effects were deemed statistically significant if $p<0.05$. The interaction terms in these models were also examined using ANCOVA to adjust for group differences on List A performance so as to evaluate performance on analogous List B measures.

Based on a number of previous studies [3], we defined a LASSI-L decrement 
on List B2 Cued Recall relative to List A2 Cued Recall of 30\% or more as indicating difficulties with frPSI. As such, we subsequently examined the extent to which different diagnostic groups scored at an impaired frPSI ratio threshold of 0.70 or less using chi-square analyses.

\section{Results}

As depicted in Table 1, diagnostic groups did not differ with regard to age and educational attainment. Participants with aMCI exhibited lower MMSE scores as compared to their PreMCI and CN counterparts. There were a greater number of female aMCI participants than $\mathrm{CN}$ participants. The aMCI group evidenced lower frPSI ratios than the other diagnostic groups, which indicates that there was a greater failure to recover from PSI even after accounting for initial learning capacity. Despite a statistically significant F-test, group means for the PSI measure did not differ when the Tukey's post-hoc test of means was applied. There were no group differences with regards to RSI ratios.

As indicated in Table 2, which compared aMCI with CN participants, there were statistically significant main effects for both Diagnostic Groups and. Measure. This indicates that as a whole, aMCI participants obtained lower scores than $\mathrm{CN}$ on measures tapping PSI, frPSI and RSI. Most informative, however, was an inspection of the interaction term. Before statistical adjustment of initial learning capacity, only the frPSI measure obtained statistical significance indicating that greater frPSI effects were obtained for aMCI group. However, after covariate

Table 1. Comparison of aMCI and PreMCI subtypes with cognitively normal elders.

\begin{tabular}{|c|c|c|c|c|}
\hline & $\begin{array}{c}\text { CN } \\
(n=50)\end{array}$ & $\begin{array}{c}\mathrm{aMCI} \\
(\mathrm{n}=35)\end{array}$ & $\begin{array}{l}\text { PreMCI } \\
(\mathrm{n}=16)\end{array}$ & F-Value or $\mathrm{X}^{2}$ \\
\hline $\begin{array}{c}\text { Age } \\
\text { Range (60 - 92) }\end{array}$ & $\begin{array}{c}75.46 \\
(\mathrm{SD}=8.9)\end{array}$ & $\begin{array}{c}77.20 \\
(\mathrm{SD}=7.0)\end{array}$ & $\begin{array}{c}76.69 \\
(\mathrm{SD}=7.5)\end{array}$ & 0.51 \\
\hline $\begin{array}{c}\text { Education } \\
\text { Range } 11-22\end{array}$ & $\begin{array}{c}15.98 \\
(\mathrm{SD}=2.7)\end{array}$ & $\begin{array}{c}16.55 \\
(\mathrm{SD}=2.4)\end{array}$ & $\begin{array}{c}16.75 \\
(\mathrm{SD}=32)\end{array}$ & 0.70 \\
\hline Gender (\% F) & $76.0 \%$ & $45.7 \%$ & $56.3 \%$ & $8.35^{\star}$ \\
\hline $\begin{array}{c}\text { MMSE } \\
\text { Range } 22-30\end{array}$ & $\begin{array}{c}28.98^{\mathrm{b}} \\
(\mathrm{SD}=1.3)\end{array}$ & $\begin{array}{c}27.49^{\mathrm{a}} \\
(\mathrm{SD}=2.2)\end{array}$ & $\begin{array}{c}29.00^{\mathrm{b}} \\
(\mathrm{SD}=1.1)\end{array}$ & $9.20^{\star * *}$ \\
\hline $\begin{array}{c}\text { LASSI-L PSI Ratio } \\
\text { List B Free Recall } 1 / \text { List A } \\
\text { Free Recall } 1\end{array}$ & $\begin{array}{c}0.769 \\
(\mathrm{SD}=0.27)\end{array}$ & $\begin{array}{c}0.810 \\
(\mathrm{SD}=0.46)\end{array}$ & $\begin{array}{c}0.746 \\
(\mathrm{SD}=0.25)\end{array}$ & 0.24 \\
\hline $\begin{array}{c}\text { LASSI-L PSI Ratio } \\
\text { List B Cued Recall 1/List A } \\
\text { Cued Recall } 1\end{array}$ & $\begin{array}{c}0.727 \\
(\mathrm{SD}=0.25)\end{array}$ & $\begin{array}{c}0.591 \\
(\mathrm{SD}=0.27)\end{array}$ & $\begin{array}{c}0.748 \\
(\mathrm{SD}=0.29)\end{array}$ & $3.25^{*}$ \\
\hline $\begin{array}{c}\text { LASSI-L frPSI Ratio } \\
\text { List B Cued Recall 2/List A } \\
\text { Cued Recall } 2\end{array}$ & $\begin{array}{l}0.860^{\mathrm{b}} \\
(0.16)\end{array}$ & $\begin{array}{l}0.700^{\mathrm{a}} \\
(0.14)\end{array}$ & $\begin{array}{l}0.748^{\mathrm{a}} \\
(0.17)\end{array}$ & $11.45^{* * *}$ \\
\hline $\begin{array}{c}\text { LASSI-L RSI Ratio } \\
\text { List A Cued Recall 3/List A } \\
\text { Cued Recall } 3\end{array}$ & $\begin{array}{l}0.648 \\
(0.18)\end{array}$ & $\begin{array}{l}0.590 \\
(0.17)\end{array}$ & $\begin{array}{l}0.550 \\
(0.18)\end{array}$ & 2.29 \\
\hline
\end{tabular}

Note: ${ }^{*} \mathrm{p}<0.05 ;{ }^{* *} \mathrm{p}<0.01 ;{ }^{* *} \mathrm{p}<0.001$. Means with different alphabetic superscripts are statistically significant at $\mathrm{p}<0.05$ by the Tukey's Honestly Significant Difference Test HSD. 
Table 2. Comparative performance on LASSI-Measures for aMCI versus CN with and without adjustment for initial memory performance.

\begin{tabular}{|c|c|c|c|c|}
\hline & $\begin{array}{l}\text { Cognitively } \\
\text { Normal } \\
(\mathrm{n}=50)\end{array}$ & $\begin{array}{c}\text { aMCI } \\
(\mathrm{n}=35)\end{array}$ & $\begin{array}{l}\text { F-Value Measure } \\
\text { Group: Group X } \\
\text { Measure Interaction }\end{array}$ & $\begin{array}{c}\text { Interaction Term } \\
\text { Adjusted for Initial } \\
\text { Performance on A } \\
\text { Targets }\end{array}$ \\
\hline \multicolumn{5}{|l|}{ PSI Free Recall } \\
\hline List A1 Free Recall & $\begin{array}{c}9.56 \\
(\mathrm{SD}=2.3)\end{array}$ & $\begin{array}{c}6.74 \\
(\mathrm{SD}=2.8)\end{array}$ & Measure $\mathrm{F}=55.54^{\star * *}$ & \multirow{3}{*}{$\begin{array}{l}\text { Interaction } \mathrm{F}=10.78^{* *} \\
\text { (Adjusting for Free A1) }\end{array}$} \\
\hline Versus & & & Group $F=40.71^{* * *}$ & \\
\hline $\begin{array}{l}\text { List B1 Free } \\
\text { Recall }\end{array}$ & $\begin{array}{c}7.22 \\
(\mathrm{SD}=2.5)\end{array}$ & $\begin{array}{c}4.57 \\
(\mathrm{SD}=1.8)\end{array}$ & Interaction $\mathrm{F}=0.078$ & \\
\hline \multicolumn{5}{|l|}{ PSI Cued Recall } \\
\hline List A1 Cued Recall & $\begin{array}{c}10.48 \\
(\mathrm{SD}=2.1)\end{array}$ & $\begin{array}{c}8.17 \\
(\mathrm{SD}=2.3)\end{array}$ & Measure $\mathrm{F}=122.19^{* * \star}$ & \multirow{3}{*}{$\begin{array}{l}\text { Interaction } \mathrm{F}=18.01^{\star *} \\
\text { (Adjusting for Cued A1) }\end{array}$} \\
\hline Versus & & & Group $F=34.16^{* * *}$ & \\
\hline $\begin{array}{l}\text { List B1 Cued } \\
\text { Recall }\end{array}$ & $\begin{array}{c}7.46 \\
(\mathrm{SD}=2.6)\end{array}$ & $\begin{array}{c}4.74 \\
(\mathrm{SD}=2.4)\end{array}$ & Interaction $\mathrm{F}=0.491$ & \\
\hline \multicolumn{5}{|l|}{ frPSI Cued Recall } \\
\hline List A2 Cued Recall & $\begin{array}{c}13.18 \\
(\mathrm{SD}=1.6)\end{array}$ & $\begin{array}{c}1.32 \\
(\mathrm{SD}=2.4)\end{array}$ & Measure $\mathrm{F}=159.6^{\star * *}$ & \multirow{3}{*}{$\begin{array}{l}\text { Interaction } \mathrm{F}=18.89^{* * *} \\
\text { (Adjusting for Cued A2) }\end{array}$} \\
\hline Versus & & & Group $F=45.52^{\star * *}$ & \\
\hline List B Cued 2 Recall & $\begin{array}{c}11.49 \\
(\mathrm{SD}=1.6)\end{array}$ & $\begin{array}{c}8.03 \\
(\mathrm{SD}=1.9)\end{array}$ & Interaction $\mathrm{F}=14.40^{\star * *}$ & \\
\hline \multicolumn{5}{|l|}{ RSI Cued Recall } \\
\hline List A3 Cued Recall & $\begin{array}{c}13.18 \\
(\mathrm{SD}=1.6)\end{array}$ & $\begin{array}{c}11.49 \\
(\mathrm{SD}=1.6)\end{array}$ & Measure $\mathrm{F}=332.85^{\star * \star}$ & \multirow{3}{*}{$\begin{array}{c}\text { Interaction } F=3.35 \\
\text { (Adjusting for Cued A2) }\end{array}$} \\
\hline Versus & & & Group $\mathrm{F}=24.38^{* * *}$ & \\
\hline List B Cued 2 Recall & $\begin{array}{c}8.52 \\
(\mathrm{SD}=2.5)\end{array}$ & $\begin{array}{c}6.74 \\
(\mathrm{SD}=2.0)\end{array}$ & Interaction $\mathrm{F}=0.026$ & \\
\hline
\end{tabular}

Note: ${ }^{*} \mathrm{p}<0.05 ;{ }^{* *} \mathrm{p}<0.01 ;{ }^{* * *} \mathrm{p}<0.001$. Means with different alphabetic superscripts are statistically significant at $\mathrm{p}<0.05$ by the Tukey's Honestly Significant Difference Test HSD.

adjustment, aMCI participants demonstrated greater difficulties with both PSI and frPSI effects than did CN participants. In Table 3, both adjusted and non-adjusted interaction terms were only statistically significant for PreMCI participants, and indicated more difficulties in frPSI relative to their CN counterparts. Neither PreMCI nor aMCI groups demonstrated any difference in RSI effects relative to $\mathrm{CN}$ group.

We previously established a cut-point of $70 \%$ or less on the frPSI ratio to indicate that there was at least a $30 \%$ decrement in maximum cued recall on LASSI-L List 2 Cued Recall, versus the maximum cued recall On LASSI-L List B2 recall. A chi-square analysis indicates that $14.0 \%$ of $\mathrm{CN}$ individuals scored lower than 0.70 on the frPSI ratio, relative to $43.8 \%$ of PreMCI and $50 \%$ of aMCI participants, respectively $\left[\mathrm{X}^{2}(\mathrm{df}=2)=13.71 ; \mathrm{p}=0.001\right]$. Post-hoc chi-square tests with Yate's Correction for Discontinuity showed a difference between $\mathrm{CN}$ and PreMCI $\left[\mathrm{X}^{2}(\mathrm{df}=1)=4.76 ; \mathrm{p}=0.029\right]$, as well as $\mathrm{CN}$ and aMCI $\left[\mathrm{X}^{2}(\mathrm{df}=1)=\right.$ 11.15; $\mathrm{p}=0.001]$. We found that PreMCI and aMCI did not differ with regard to 
Table 3. Comparative performance on LASSI-Measures for PreMCI versus CN with and without adjustment for initial memory performance.

\begin{tabular}{|c|c|c|c|c|}
\hline & $\begin{array}{l}\text { Cognitively } \\
\text { Normal } \\
(n=50)\end{array}$ & $\begin{array}{l}\text { PreMCI } \\
(n=16)\end{array}$ & $\begin{array}{c}\text { F-Value Measure } \\
\text { Group: Group X } \\
\text { Measure Interaction }\end{array}$ & $\begin{array}{c}\text { Interaction Term } \\
\text { Adjusted for Initial } \\
\text { Performance on List A } \\
\text { Targets }\end{array}$ \\
\hline \multicolumn{5}{|l|}{ PSI Free Recall } \\
\hline List A1 Free Recall & $\begin{array}{c}9.56 \\
(\mathrm{SD}=2.3)\end{array}$ & $\begin{array}{c}8.25 \\
(\mathrm{SD}=2.7)\end{array}$ & Measure $\mathrm{F}=43.91^{\star \star *}$ & \multirow{3}{*}{$\begin{array}{c}\text { Interaction } F=0.568 \\
\text { (Adjusting for Free A1) }\end{array}$} \\
\hline Versus & & & Group $F=0.4 .22^{\star}$ & \\
\hline $\begin{array}{l}\text { List B1 Free } \\
\text { Recall }\end{array}$ & $\begin{array}{c}7.22 \\
(\mathrm{SD}=2.5)\end{array}$ & $\begin{array}{c}6.00 \\
(\mathrm{SD}=2.6)\end{array}$ & Interaction $\mathrm{F}=0.017$ & \\
\hline PSI Cued Recall & \multicolumn{4}{|c|}{ Measure } \\
\hline List A1 Cued Recall & $\begin{array}{c}10.48 \\
(\mathrm{SD}=2.1)\end{array}$ & $\begin{array}{c}9.13 \\
(\mathrm{SD}=2.2)\end{array}$ & $\mathrm{F}=47.26^{\star * \star}$ & \multirow{3}{*}{$\begin{array}{c}\text { Interaction } \mathrm{F}=0.073 \\
\text { (Adjusting for Cued A1) }\end{array}$} \\
\hline Versus & & & Group $F=3.71$ & \\
\hline $\begin{array}{l}\text { List B1 Cued } \\
\text { Recall }\end{array}$ & $\begin{array}{c}7.46 \\
(\mathrm{SD}=2.6)\end{array}$ & $\begin{array}{c}6.69 \\
(\mathrm{SD}=2.7)\end{array}$ & Interaction $\mathrm{F}=0.538$ & \\
\hline \multicolumn{5}{|l|}{ frPSI Cued Recall } \\
\hline List A2 Cued Recall & $\begin{array}{c}13.18 \\
(\mathrm{SD}=1.6)\end{array}$ & $\begin{array}{c}13.13 \\
(\mathrm{SD}=1.6)\end{array}$ & Measure $F=77.09^{* * \star}$ & \multirow{3}{*}{$\begin{array}{l}\text { Interaction } \mathrm{F}=6.81{ }^{* *} \\
\text { (Adjusting for Cued A2) }\end{array}$} \\
\hline Versus & & & Group $F=2.76$ & \\
\hline List B Cued 2 Recall & $\begin{array}{c}11.49 \\
(\mathrm{SD}=1.6)\end{array}$ & $\begin{array}{c}9.75 \\
(\mathrm{SD}=2.1)\end{array}$ & Interaction $\mathrm{F}=6.46^{* *}$ & \\
\hline \multicolumn{5}{|l|}{ RSI Cued Recall } \\
\hline List A3 Cued Recall & $\begin{array}{c}13.18 \\
(\mathrm{SD}=1.6)\end{array}$ & $\begin{array}{c}13.13 \\
(\mathrm{SD}=3.4)\end{array}$ & Measure $\mathrm{F}=242.55^{\star * *}$ & \multirow{3}{*}{$\begin{array}{c}\text { Interaction } \mathrm{F}=3.53 \\
\text { (Adjusting for Cued A2) }\end{array}$} \\
\hline Versus & & & Group $F=1.81$ & \\
\hline List B Cued 2 Recall & $\begin{array}{c}8.52 \\
(\mathrm{SD}=2.5)\end{array}$ & $\begin{array}{c}7.25 \\
(\mathrm{SD}=25)\end{array}$ & Interaction $\mathrm{F}=3.23$ & \\
\hline
\end{tabular}

Note: ${ }^{*} \mathrm{p}<0.05 ;{ }^{* *} \mathrm{p}<0.01 ;{ }^{* * *} \mathrm{p}<0.001$. Means with different alphabetic superscripts are statistically significant at $\mathrm{p}<0.05$ by the Tukey's Honestly Significant Difference Test HSD.

those who scored $70 \%$ or lower on the frPSI ratio I $\left[\mathrm{X}^{2}(\mathrm{df}=1)=0.01 ; \mathrm{p}=\right.$ 0.913].

\section{Discussion}

It is increasingly recognized that cognitive stress tests may be sensitive to the earliest manifestations of neurodegenerative disease [3]. One such cognitive stress test, the LASSI-L, is unique in that it encourages maximum encoding and recall of information by employing controlled learning strategies, such as semantic cues, during the initial presentation of the word list. In addition, two competing wordlists that are semantically related and consist of 15 targets in each list are presented across free and cued recall trials in order to maximize the effects of proactive semantic interference (PSI). Further, unlike any existing measures of learning and memory, there is a second opportunity to learn the competing List B targets whereby performance difficulties may reflect a failure to recover from the initial effects of PSI (frPSI). 
Performance on the second presentation of List B (List B2) of the LASSI-L, which is vulnerable to frPSI, has shown excellent discrimination between aMCI and cognitively normal groups [4] [5] [6]. This measure (frPSI) has also demonstrated a strong relationship with brain MRI volumetric loss in AD prone areas among older adults with aMCI [7], and has been shown to be uniquely and strongly related to amyloid load in the brains of elderly community-dwelling elders who performed well on traditional neuropsychological measures [8]. Despite these previous findings, there have been questions as to whether performance on List B2 truly reflects frPSI or other cognitive deficits associated with strength of initial encoding and recall which may be associated with early neurodegenerative disease. In this study, we attempted to address this potential issue by directly comparing the ability to learn the original wordlist (List A) across two learning trials with the ability to learn the competing wordlist (List B), also across two trials, in essence, using the participant as their own control. This method allowed for examination of learning capacity on List B2 after controlling for initial learning abilities on List A (depicted by performance on List A2), which directly allowed us to capture the impact of the failure to recover from PSI.

The present results confirmed our expectation that individuals with amnestic MCI, and even those with PreMCI, had much greater frPSI effects than cognitively normal $(\mathrm{CN})$ subjects. For example, only $14 \%$ of $\mathrm{CN}$ participants achieved LASSI-L List B2 performance that was $70 \%$ or less than their performance on List A2. In contrast, as indicated in Figure 1, 43.8\% of PreMCI and 50\% of aMCI participants exhibited these frPSI deficits PSI effects were not consistently shown in most analyses. In contrast, there was no evidence of RSI effects between different study groups in any of our analyses.

Our findings that individuals with PreMCI, who otherwise had normal performance on widely used memory measures, were impacted by frPSI in a similar manner to their aMCI counterparts who are at high risk of progression to AD, points to the potential value of frPSI as measured by the LASSI-L as a preclinical cognitive marker of $\mathrm{AD}$. This raises the issue as to what it is about frPSI that makes it a sensitive measure to the effects of early cerebral dysfunction. We have previously argued that frPSI deficits may be related to deficits in source memory i.e., the semantic cues used to elicit List B cued recall are the same cues that were originally used to elicit recall of List A targets [3]. This may create difficulties in accessing source memory for the distinct List A and List B associations. These difficulties in source memory may be a challenge for all groups, even healthy aged persons with normal cognition, after the first cued recall of List B and this is supported by the obtained data. However, repeated administration of the List $B$ targets appears to allow cognitively normal individuals to better recover from initial effects, whereas those with aMCI and PreMCI likely lack the necessary compensatory mechanisms to allow them to recover from PSI effects even over a repeated learning trial. Thus, memory deficits implicated in early $\mathrm{AD}$ may be more complicated than simply the ability to learn and retain information. As 


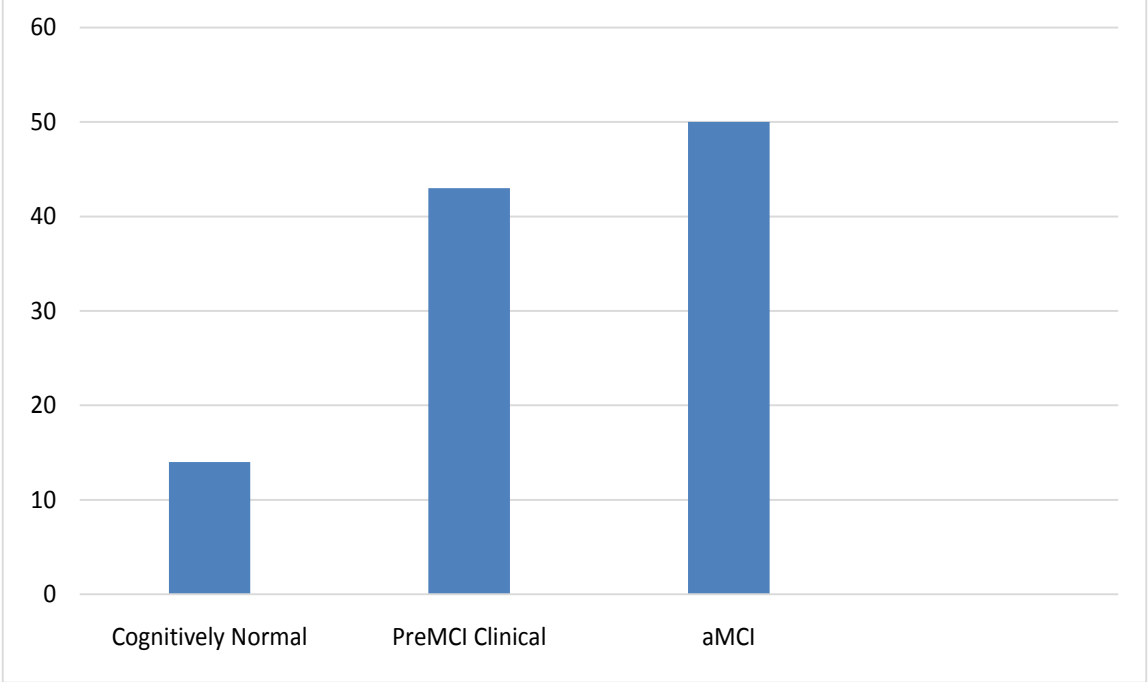

Figure 1. Percentage of participants with impairment in frPSI. $\mathrm{X}^{2}(\mathrm{df}=2)=13.71 ; \mathrm{p}=$ 0.001 .

demonstrated by the present study, even after adjusting for initial learning strength and recall, previous exposure to semantically related material appears to disrupt the learning of new information that is similar in semantic relatedness to what already has been learned.

The current investigation adds to a growing literature that a focus on proactive semantic interference, and importantly, the recovery from proactive semantic interference, may be more important than information obtained by simple proactive interference paradigms that do not solely focus on semantic relatedness of to-be-remembered information. Because there is a growing recognition that individuals with $\mathrm{AD}$ and related neurodegenerative disorders have difficulties with semantic memory and accessing semantic lexicon, a greater emphasis on instruments that tap these processes are warranted.

The strengthes of this study are to carefully work up patient groups with well-established operational criteria. Limitations include a modest sample of participants diagnosed with PreMCI. All of our participants were white, non-Hispanic, primary English-speakers. As such, it will be important to replicate these findings in different ethnic and language groups. It is clear that cognitive stress tests such as the LASSI-L, particularly with its unique measure of frPSI, show promise in investigating early detection and tracking of individuals at risk for $\mathrm{AD}$. Ongoing longitudinal studies will further elucidate the predictive utility of these types of measures with regards to progression and response to emerging treatments.

\section{Funding}

This research was supported by NIH/NIA Grant Number 1RO1AG047649-01A1 Loewenstein, David (PI). 


\section{References}

[1] Stern, Y. (2009) Cognitive Reserve. Neuropsychologia, 47, 2015-2028. https://doi.org/10.1016/j.neuropsychologia.2009.03.004

[2] Buschke, H. (2014) Rationale of the Memory Binding Test. In: Nilsson, L.-G. and Ohta, N., Eds., Dementia and Memory, Psychology Press, Hove, 55-68.

[3] Loewenstein, D.A., Curiel, R.E., Duara, R. and Buschke, H. (2017) Novel Cognitive Paradigms for the Detection of Memory Impairment in Preclinical Alzheimer's Disease. SAGE Publications, Thousand Oaks.

[4] Crocco, E., Curiel, R.E., Acevedo, A., Czaja, S.J. and Loewenstein, D.A. (2014) An Evaluation of Deficits in Semantic Cueing and Proactive and Retroactive Interference as Early Features of Alzheimer's Disease. The American Journal of Geriatric Psychiatry, 22, 889-897. https://doi.org/10.1016/j.jagp.2013.01.066

[5] Curiel, R.E., Crocco, E., Acevedo, A., Duara, R. and Agron, J. (2013) A New Scale for the Evaluation of Proactive and Retroactive Interference in Mild Cognitive Impairment and Early Alzheimer's Disease. Journal of Aging Science, 1-5.

[6] Matías-Guiu, J.A., Curiel, R.E., Rognoni, T., Valles-Salgado, M., Fernández-Matarrubia, M., Hariramani, R., Matías-Guiu, J., et al. (2017) Validation of the Spanish Version of the LASSI-L for Diagnosing Mild Cognitive Impairment and Alzheimer's Disease. Journal of Alzheimer's Disease, 56, 733-742.

[7] Loewenstein, D.A., Curiel, R.E., Wright, C., Sun, X., Alperin, N., Crocco, E., Czaja, S.J., Raffo, A., Penate, A., Melo, J., Capp, K., Gamez, M. and Duara, R. (2017) Recovery from Proactive Semantic Interference in Mild Cognitive Impairment and Normal Aging: Relationship to Atrophy in Brain Regions Vulnerable to Alzheimer's Disease. Journal of Alzheimer's Disease, 56, 1119-1126, https://doi.org/10.3233/JAD-160881

[8] Loewenstein, D.A., Curiel, R.E., Greig, M.T., Bauer, R.M., Rosado, M., Bowers, D., Rodriguez, R., et al. (2016) A Novel Cognitive Stress Test for the Detection of Preclinical Alzheimer Disease: Discriminative Properties and Relation to Amyloid Load. The American Journal of Geriatric Psychiatry, 24, 804-813.

https://doi.org/10.1016/j.jagp.2016.02.056

[9] Morris, J.C. (1993) The Clinical Dementia Rating (CDR): Current Version and Scoring Rules. Neurology, 43, 2412-2414. https://doi.org/10.1212/WNL.43.11.2412-a

[10] Folstein, M.F., Folstein, S.E. and McHugh, P.R. (1975) "Mini-Mental State": A Practical Method for Grading the Cognitive State of Patients for the Clinician. Journal of Psychiatric Research, 12, 189-198. https://doi.org/10.1016/0022-3956(75)90026-6

[11] Benedict, R.H., Schretlen, D., Groninger, L. and Brandt, J. (1998) Hopkins Verbal Learning Test-Revised: Normative Data and Analysis of Inter-Form and Test-Retest Reliability. The Clinical Neuropsychologist, 12, 43-55. https://doi.org/10.1076/clin.12.1.43.1726

[12] Weintraub, S., Salmon, D., Mercaldo, N., Ferris, S., Graff-Radford, N.R., Chui, H., Peskind, E., et al. (2009) The Alzheimer's Disease Centers' Uniform Data Set (UDS): The Neuropsychological Test Battery. Alzheimer Disease and Associated Disorders, 23, 91-101. https://doi.org/10.1097/WAD.0b013e318191c7dd

[13] Ruff, R.M., Light, R.H., Parker, S.B. and Levin, H.S. (1996) Benton Controlled Oral word Association Test: Reliability and Updated Norms. Archives of Clinical Neuropsychology, 11, 329-338. https://doi.org/10.1093/arclin/11.4.329

[14] Wechsler, D. (2014) Wechsler Adult Intelligence Scale. 4th Edition, Psychological 
Corporation, San Antonio.

[15] Reitan, R.M. (1958) Validity of the Trail Making Test as an Indicator of Organic Brain Damage. Perceptual and Motor Skills, 8, 271-276.

https://doi.org/10.2466/pms.1958.8.3.271 